\title{
Prevalence of Hypertension and Associated Risk Factors Among Al-Azhar University Male Students Hostel Cairo, Egypt
}

\author{
Abdel Wahab Mohamed Lotfy ${ }^{1}$, MD; Ismail Mohamed Elmancy ${ }^{1}$, MD; Tahseen Samir Mohamed ${ }^{2}$, MD; \\ Ibrahem Metwally Byoumy ${ }^{3}$, MD; Mohamed Gamal Tawfiq Mohamed ${ }^{1 *}$, M.B.B.Ch
}

\section{*Corresponding Author \\ Mohamed Gamal Tawfiq Mohamed gemydiabb@gmail.com}

Received for publication February 2, 2020; Accepted June 4, 2020;

Published online June, 5, 2020

Copyright 2020 The Authors published by Al-Azhar University, Faculty of Medicine, Cairo, Egypt. All rights reserved. This an open-access article distributed under the legal terms, where it is permissible to download and share the work provided it is properly cited. The work cannot be changed in any way or used commercially.

doi: 10.21608/aimj.2020.23384.1124

${ }^{1}$ Department of Internal Medicine, Faculty of Medicine, Al-Azhar University, Cairo, Egypt

${ }^{2}$ Department of Public Health and Community Medicine - Faculty of Medicine, Al-Azhar University, Cairo, Egypt

${ }^{3}$ Department of Clinical Pathology, AlAzhar University, Cairo, Egypt.

\section{ABSTRACT}

Background: Hypertension is considered as a public health problem worldwide because of its high frequency and concomitant risk for morbidities.

Aim: To identify the prevalence of hypertension and associated factors among Al-Azhar university male students in Cairo, Egypt.

Patients and Methods: According to the official: the total number of students is (7620) Divided into 9 buildings. The sample size was (20\%) of the total number of students. The sample was chosen by systematic random technique from 9 buildings of students hostel in Al-Azhar University in Naser City, Cairo, Egypt. A selfadministered questionnaire including weight, height, waist circumference, and a lab investigation was done.

Results: The prevalence of hypertension represents (6.1\%). the most prevalent factors associated with hypertension in this study; positive family history $(65.2 \%)$ followed by excessive salt in diet $(58.7 \%)$, stress (55.4\%), smoking (47.8\%), Obesity (26.1\%), physical activity $(1.1 \%)$.

Conclusions and recommendations: The findings of the present study highlighted the prevalence of hypertension is $6.1 \%$ among students at Al-Azhar University. The blood pressure values increased with associated factors (age, sex, BMI, smoking stress, physical activity, and family history). The current results were recommended that a periodic screening and monitoring of blood pressure of students should be incorporated into the university entrance physical examination, and university students' health education on hypertension as a disease and its associated factors should be strengthened.

Keywords: Hypertension, .associated Factors, University Male Students Hostel.

Disclosure: The authors have no financial interest to declare in relation to the content of this article. The Article Processing Charge was paid for by the authors.

Authorship: All authors have a substantial contribution to the article

\section{INTRODUCTION}

Cardiovascular diseases are becoming more prevalent in developing countries, particularly in urban areas. The World Health Organization (WHO) conference on a "second wave" epidemic of cardiovascular disease connected with arterial sclerosis predicted that in 2020 cardiovascular diseases will most likely be the leading cause of death in world ${ }^{1}$.

Thus, cardiovascular diseases must be targeted at a primary health promotion level before some of the important underlying causes of cardiovascular disease seriously afflict a person or a population at large ${ }^{2}$.

Some of the lifestyle-related risk factors for cardiovascular disease are an unhealthy diet, physical inactivity, and tobacco use, as well as the intermediate manifestations of these lifestyles, hypertension, glucose intolerance, and hyperlipidemia ${ }^{3}$.

Hypertension is cardiovascular disease, becoming a common health problem worldwide because of increasing longevity and the prevalence of contributing factors. Hypertension plays a major etiologic role in the development of the cerebrovascular disease, ischemic heart disease, cardiac failure, and renal failure ${ }^{3,4}$. 
The Egyptian National Hypertension survey of adults conducted in six Egyptian governorates estimated the prevalence of hypertension as $(26.3 \%)^{5}$.

The study aimed to identify the prevalence of hypertension and associated factors. The studied group at -Azhar University, Cairo, Egypt.

\section{PATIENTS AND METHODS}

The survey of the literature was based on: World health organization publications and reports, Local and national libraries, periodical medical journals, Trusted web sites, and previous researches (national and international).

Inclusion criteria: Students of Al-Azhar University Male Students Hostel in Cairo, Egypt.

Exclusion criteria: diagnosed cases of hypertension, chronic illnesses such as diabetes, and renal disease.

Sample size: Sample size is determined by the following formula:

Prevalence of disease or problem under study, required confidence limit and $\alpha$ error, conventionally the confidence is $95 \%$ and $\alpha$ is 0.05 and Required Precision $(\delta)$. S P $=$ prevalence 1.96 $=\mathrm{Z}$ score at $\alpha=0.3$. Sample size $(\mathrm{n})=(1.96) 2 \mathrm{X} \mathrm{P}$ $(1-\mathrm{P}) / \mathrm{d} 2$. Were $\mathrm{P}=.7 \%$ and $\mathrm{d}=.25 \%$.

So the sample size $=1424$ we estimate it as 1500 . The official records of the total number of students are (7620). Divided into 9 buildings. The sample size was $(20 \%)$ of a total number of students (1500) was chosen by using the systematic random technique from 9 buildings of students hostel using students list of the hostel (if one of the students were absent the following student on the list was chosen, to constitute the study sample) in Al-Azhar University in Naser City, Cairo, Egypt.

Filed work: The data were collected during the period from the November2018and to the end of May 2019. The researcher arranged with the director of a hostel for the proper available days for data collection in which all students were available in the hostel, the researcher started to collect data two times per week. Data were collected using a selfconstructed face-to-face interviewed questionnaire: each student took20-30 minutes to complete the tool and to perform physical measurements at the manner of privacy in the presence of researchers,

Data collection:-

The data were collected using the following tools: Structured interview questionnaire

A structured interview questionnaire sheet was modified by the researchers to meet the aims of the study, based on the literature review and was written in simple Arabic language to suit the students' level of understanding. Socio-Demographics

characteristics were collected as age, gender, marital status, residence education degree, health behaviors smoking status, physical activity, and nutritional lifestyle and family history ${ }^{19}$.

This is to

formulate the final form of the research tools. determine the time needed to conduct the interview. Proper blood pressure measurement requires the person whose blood pressure is being measured to sit quietly for at least five minutes which is then followed by the application of a properly fitted blood pressure cuff to a bare upper arm. The person whose blood pressure is being measured should avoid talking or moving during this process. The arm being measured should be supported on a flat surface at the level of the heart ${ }^{6}$.

Blood pressure measurement was done in a quiet room so the researcher checking the blood pressure can hear the Korotkoff sounds while listening to the brachial artery with a stethoscope. The blood pressure cuff should be deflated slowly $(2-3 \mathrm{mmHg}$ per second) while listening for the Korotkoff sounds. The bladder was emptied before a person's blood pressure is measured since this can increase blood pressure by up to $15 / 10 \mathrm{mmHg}$. Multiple blood pressure readings (at least two) spaced 1-2 minutes apart should be obtained to ensure accuracy ${ }^{7}$.

Body mass index (BMI) measurements:

BMI was categorized according to the World Health Organization criteria, where a BMI of $<25 \mathrm{~kg} / \mathrm{m} 2$ is considered normal, a BMI between 25 and $29 \mathrm{~kg} / \mathrm{m} 2$ is considered overweight, and a BMI $>30 \mathrm{~kg} / \mathrm{m} 2$ is considered obese. Weight and height were measured and BMI was calculated as weight in kilograms divided by height in meters squared. Every student was weighed using an electronic standardized weight scale. The student was weighed without outdoor garments and shoes. Height was measured to the nearest $0.1 \mathrm{~cm}$. All measurements were taken using a non-stretch measuring tape. Shoes were removed and the height was recorded to the nearest $\mathrm{cm}$.

Statistical analysis: Data were analyzed using the Statistical Package of Social Science (SPSS) program for Windows (Standard version 22). The normality of data was first tested with a one-sample Kolmogorov-Smirnov test. Continuous variables were presented as mean $\pm \mathrm{SD}$ (standard deviation). Pearson correlation was used to correlate continuous data. p-value $\leq 0.3$ was accepted as a level of significance.

\section{RESULTS}

Table (1) and Figure (1) show that among 1500 examined students, 92 students were hypertensive represent $(6.1 \%)$ while 1408 students were normotensive $(93.9 \%)$.

\begin{tabular}{|lc|}
\multicolumn{1}{|c}{$\begin{array}{c}\text { Prevalence of } \\
\text { hypertension }\end{array}$} & $\begin{array}{c}\text { Study group } \\
(\mathbf{n}=\mathbf{1 5 0 0 )}\end{array}$ \\
\hline $\begin{array}{l}\text { Hypertensive } \\
\text { Normotensive }\end{array}$ & $92(6.1 \%)$ \\
\hline
\end{tabular}

Table (1): Prevalence of hypertension among the studied students

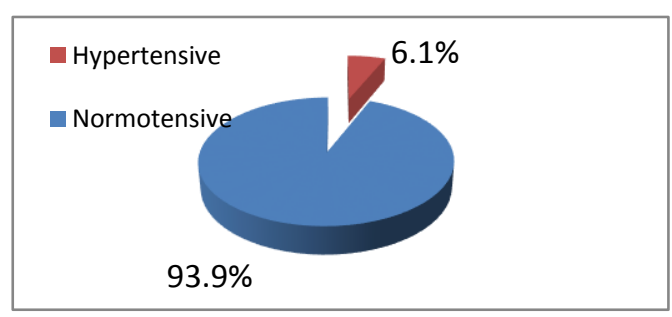

Figure (1): Prevalence of hypertension among the studied students 
Lotfy et al , Hypertension Among Al-Azhar University Male Students

Table (2) shows that the mean age of the studied hypertensive students was $22.43 \pm 1.59$ ranged from $19 \mathrm{y}$ to $25 \mathrm{y}$.

\begin{tabular}{|cc|}
\hline Age (years) & $\begin{array}{c}\text { Study group } \\
(\mathbf{n}=92)\end{array}$ \\
\hline Age (years) & \\
Mean \pm SD & $22.43 \pm 1.59$ \\
Min-Max & $19.00-25.00$ \\
$\mathbf{1 9 -}$ & $1(1.1 \%)$ \\
$\mathbf{2 0 -}$ & $9(9.8 \%)$ \\
$\mathbf{2 1 -}$ & $26(28.3 \%)$ \\
$\mathbf{2 2 -}$ & $4(4.3 \%)$ \\
$\mathbf{2 3 -}$ & $28(30.4 \%)$ \\
$\mathbf{2 4 -}$ & $13(14.1 \%)$ \\
$\mathbf{2 5} \mathbf{y}$ & $11(12 \%)$ \\
\hline
\end{tabular}

Table (2): Age distribution among hypertensive students

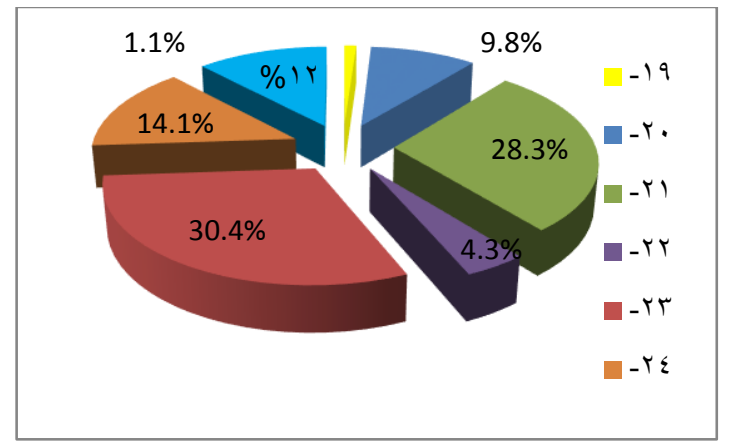

Figure (2): Age distribution among hypertensive students

Table (3) and Figure (3) shows that the most prevalent associated factors for hypertension were the following; positive family history (65.2\%) followed by excessive salt in diet $(58.7 \%)$, stress (55.4\%), smoking (47.8\%), Obesity $(26.1 \%)$ and Physical activity $(1.1 \%)$.

\begin{tabular}{|c|c|}
\hline associated factors & $\begin{array}{c}\text { Study group } \\
(\mathbf{n}=92)\end{array}$ \\
\hline $\begin{array}{c}\text { Smoking } \\
\text { Yes }\end{array}$ & $44(47.8 \%)$ \\
No & $48(52.2 \%)$ \\
\hline Family history & \\
Positive & $60(65.2 \%)$ \\
Negative & $32(34.8 \%)$ \\
\hline Physical activity & \\
Positive & $1(1.1 \%)$ \\
Negative & $91(98.9 \%)$ \\
\hline Obesity & $13(14.1 \%)$ \\
Normal & $55(59.8 \%)$ \\
\hline Overweight & $24(26.1 \%)$ \\
Obese & \\
\hline Stress & \\
Yes & $51(55.4 \%)$ \\
No & $41(44.6 \%)$ \\
\hline
\end{tabular}

\section{Excessive salt in the diet}

Yes

$54(58.7 \%)$

No

$38(41.3 \%)$

Table (3): associated factors among hypertensive students

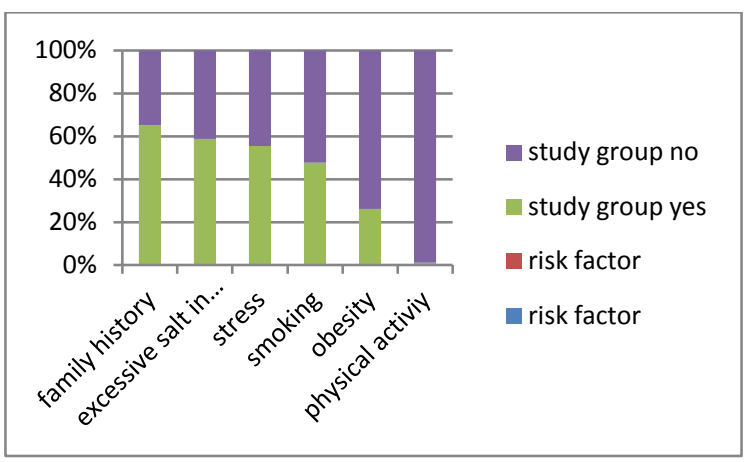

Figure (3): associated factors among hypertensive students

Table (4): shows the anthropometric measurements among hypertensive students.

\begin{tabular}{|cc|}
\hline $\begin{array}{c}\text { Anthropometric } \\
\text { measurements }\end{array}$ & $\begin{array}{c}\text { Study group } \\
(\mathbf{n}=92)\end{array}$ \\
\hline Weight & \\
Mean \pm SD & $88.57 \pm 14.02$ \\
Range & $68.00-140.00$ \\
\hline Height & \\
Mean \pm SD & $175.62 \pm 3.64$ \\
Range & $162.00-187.00$ \\
\hline BMI & \\
Mean \pm SD & $28.73 \pm 4.84$ \\
Range & $20.99-47.32$ \\
\hline
\end{tabular}

Table (4): Anthropometric measurements among hypertensive students

Table (5) and Figure (4) shows the blood pressure among hypertensive students.

\begin{tabular}{|c|c|}
\hline Blood pressure & $\begin{array}{c}\text { Study group } \\
(\mathbf{n}=92)\end{array}$ \\
\hline SBP & $151.74 \pm 6.64$ \\
Mean \pm SD & $145.00-170.00$ \\
Range & \\
\hline DBP & $93.58 \pm 4.76$ \\
Mean \pm SD & $90.00-100.00$ \\
Range & $89(96.7 \%)$ \\
\hline Hypertensive Grade $-\mathbf{I}$ & $3(3.3 \%)$ \\
\hline
\end{tabular}

Table (5): Blood pressure among hypertensive students 


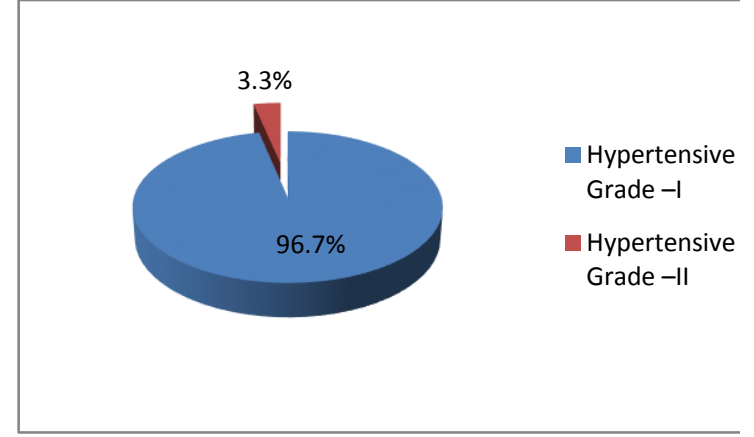

Figure (4): Hypertension grade among the studied group

Table (6) and Figure (5) shows the laboratory investigations among hypertensive students.

\begin{tabular}{|c|c|}
\hline Laboratory investigations & $\begin{array}{l}\text { Study group } \\
(\mathrm{n}=92)\end{array}$ \\
\hline $\begin{array}{l}\text { Serum creatinine } \\
\text { Mean } \pm \text { SD } \\
\text { Range }\end{array}$ & $\begin{array}{c}0.77 \pm 0.08 \\
0.70-1.10\end{array}$ \\
\hline $\begin{array}{l}\text { Cholesterol } \\
\text { Mean } \pm \text { SD } \\
\text { Range }\end{array}$ & $\begin{array}{c}160.76 \pm 36.50 \\
121.00-260.00\end{array}$ \\
\hline $\begin{array}{l}\text { Triglyceride } \\
\text { Mean } \pm \text { SD } \\
\text { Range }\end{array}$ & $\begin{array}{l}101.61 \pm 28.93 \\
70.00-235.00\end{array}$ \\
\hline $\begin{array}{l}\text { Random blood sugar } \\
\text { Mean } \pm \text { SD } \\
\text { Range }\end{array}$ & $\begin{array}{l}128.01 \pm 25.10 \\
89.00-186.00\end{array}$ \\
\hline
\end{tabular}

Table (6): Laboratory investigations among hypertensive students

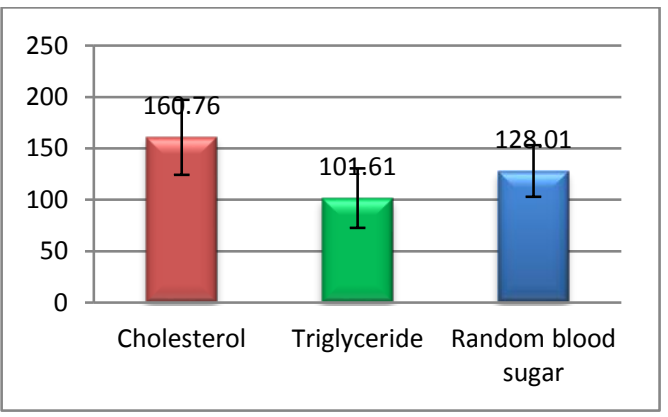

Figure (5): Mean cholesterol, TGs, and RBS among hypertensive students

\begin{tabular}{|l|c|c|}
\multicolumn{1}{|c}{ Variables } & \multicolumn{2}{c|}{ SBP } \\
\hline Age & -0.020 & p- value \\
\hline Weight & 0.348 & 0.848 \\
\hline Height & -0.006 & 0.952 \\
\hline BMI & 0.340 & $0.001^{*}$ \\
\hline Serum creatinine & -0.092 & 0.381 \\
\hline Cholesterol & 0.457 & $<0.001^{*}$ \\
\hline Triglyceride & 0.357 & $0.001^{*}$ \\
\hline
\end{tabular}

Table (7): Correlation between SBP and other variables

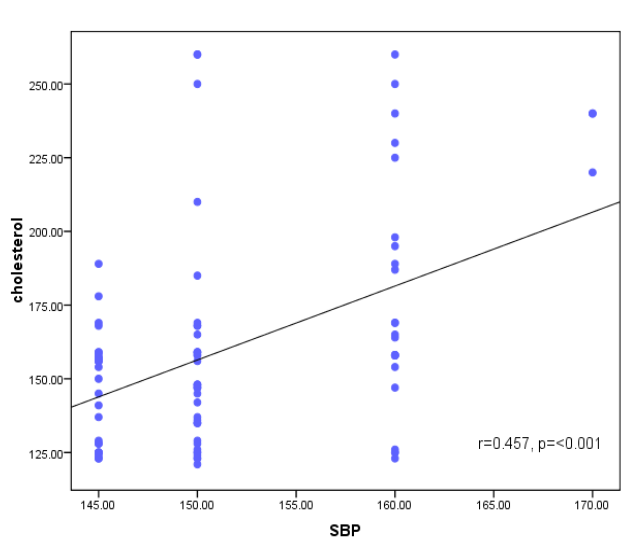

Figure (6): Scatter diagram for the positive correlation between SBP and cholesterol

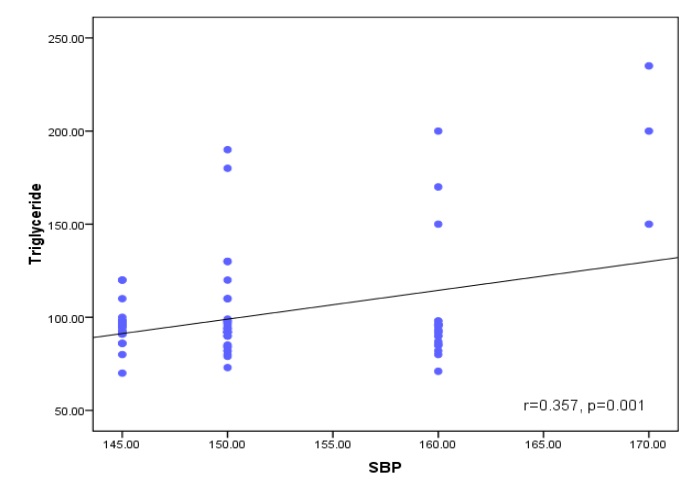

Figure (7): Scatter diagram for the positive correlation between SBP and triglycerides

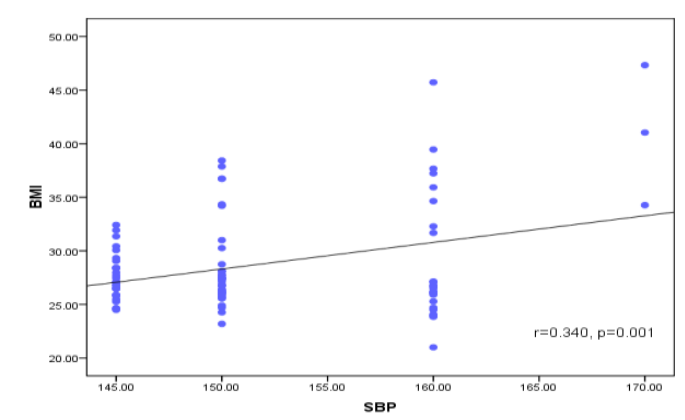

Figure (8): Scatter diagram for the positive correlation

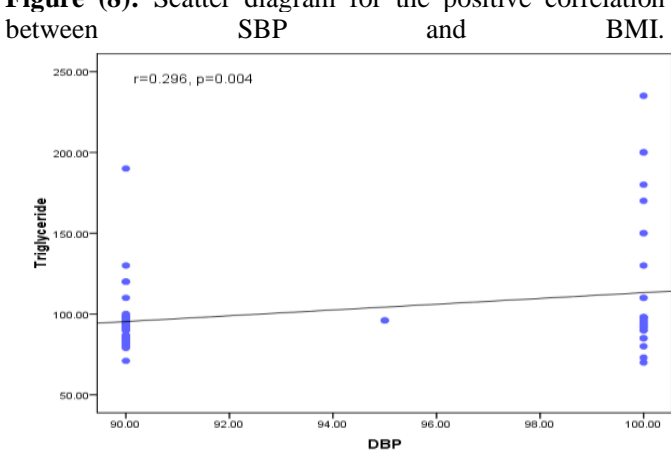

Figure (9): Scatter diagram for the positive correlation between DBP and TGs

Table (7) and figures (6-9) shows that, there was statistically significant positive correlation between SBP and weight $(r=0.348,0.002)$ also positively 
correlated with BMI ( $\mathrm{r}=0.340, \mathrm{p}=0.001)$, Cholesterol $(\mathrm{r}=0.457, \quad \mathrm{p}=<0.001), \quad$ Triglyceride $\quad(\mathrm{r}=0.357$, $\mathrm{p}=0.001)$.

Increased weight, BMI, cholesterol, triglyceride were associated with increased SBP.

\begin{tabular}{|l|c|c|}
\multicolumn{1}{c}{ Variables } & \multicolumn{2}{c|}{ DBP } \\
\hline Age & r & p- value \\
\hline Weight & -0.063 & 0.553 \\
\hline Height & 0.240 & $0.021^{*}$ \\
\hline BMI & -0.120 & 0.255 \\
\hline Serum creatinine & 0.253 & $0.015^{*}$ \\
\hline Cholesterol & -0.180 & 0.086 \\
\hline Triglyceride & 0.163 & 0.122 \\
\hline
\end{tabular}

Table (8): Correlation between DBP and other variables

Table (8) and Figure (8) shows that, there was statistically significant positive correlation between DBP and weight $(r=0.240, p=0.021)$ also positively correlated with BMI $(\mathrm{r}=0.253, \mathrm{p}=0.015)$, Triglyceride $(r=0.296, p=0.004)$.

Increased weight, BMI, and triglyceride were associated with increased DBP.

\section{DISCUSSION}

Hypertension is a disease which leads to other serious medical complication that is why it is a public health problem worldwide, especially in developing countries Hypertension increased progressively in young age groups over the past 20 years. The National Hypertension Project results indicated that hypertension is highly prevalent in Egypt, and the awareness, treatment, and control are relatively limited ${ }^{17}$

Our results are consistent with studies included in the review of Africa, the prevalence of elevated blood pressure varied widely from $0.2 \%$ to $24.8 \%$. Prevalence in different UNSD regions in Africa was 9.8-10.1\% (Central), 6.5-17.1\% (Eastern), 4.8$19.7 \%$ (Northern), $4 \cdot 5-21 \cdot 2 \%$ (Southern), and $0 \cdot 2-$ $24.8 \%$ (Western). Prevalence was between $4.1 \%$ and $11.2 \%$ in rural areas, $0.2 \%$ and $24.8 \%$ in urban areas $^{8}$.

A key finding of these studies is the substantial association of the prevalence of elevated blood pressure with increased $\mathrm{BMI}^{8}$ as shown in (Table 7, 8) (Figure 8).

Our results are not consistent with other studies among students of Ghana, $26.1 \%$ of the participants had hypertension; this is similar to the $27.1 \%$ prevalence which was found in a university in Palestine. However, other studies have found a higher prevalence of hypertension among undergraduate students such as $42.9 \%$ in Malaysian University, $40.0 \%$ in Columbia, and $39.5 \%$ in Kuwait ${ }^{9}$.

The prevalence of hypertension obtained in our present study was $6.1 \%$; shown on(Table 1) (Figure 1) which is lower than $7.4 \%$ hypertension prevalence found among university students in Gondar, Ethiopia, $19.3 \%$ prevalence of hypertension reported in a study from Nigeria, $35.1 \%$ among students from a study in Tunisia and $38.0 \%$ among university students from a study in Gambia ${ }^{9}$.

In Egypt our results are consistent with the Study of hypertension among Fayoum University students their results revealed that the global initial prevalence of hypertension in the first visit was (10.3\%) dropped to $(5.7 \%)$ in the third visit ${ }^{10}$.

In Egypt our results are not consistent with the study of hypertension was $26.5 \%$ among students in Damietta University compared to $18.1 \%$ among students in Port Said University. This result is in line with a study conducted on Iranian college students revealing the prevalence of hypertension ${ }^{11}$.

In the present study, family history was the factor most strongly associated with hypertension in the students shown in (Table 3) (Figure 3). This result is congruent with Naimet al. ${ }^{12}$ andAbd El-Mohsen et al. ${ }^{13}$ who emphasized that in Turkey if one parent was hypertensive, the probability of their children being hypertensive may be $28 \%$. If both the parents are hypertensive, the probability of their children being hypertensive may be $41.0 \%$. This study strongly supports the fact that the increase in the prevalence of adolescent hypertension is highly significant among parents with hypertension.

The present study indicated that BMI is highly associated with a higher prevalence of hypertension among university students shown in (Table 7, 8) (Figure 8). This result was agreed with Oladapo et al. ${ }^{15}$ who demonstrated a significant relationship between hypertension in university students with a BMI this result is in line with Pang et al. ${ }^{16}$ who had confirmed that obesity and being overweight were the major risk factors in hypertension.

The present study emphasized those students who smoked, had a relationship with hypertension shown in (Table 3) (Figure 3). This finding was congruent with Sundar et al. ${ }^{14}$ and Ibrahim ${ }^{17}$ who reported that increased risk of hypertension was directly associated with an increase of daily cigarette smoking. Furthermore, Abd El-Mohsen et al. ${ }^{13}$ reported that smoking and hypertension were known to accelerate the development of the process of atherosclerosis and increase the risk of all other coronary lesions ${ }^{13,17}$.

It was observed from the current results that, the prevalence of hypertension was more common among those students under stress shown in (Table 3) (Figure 3). As well as, the results indicated a significant relationship between stress and hypertension. This is consistent with the findings of a study done in Fayoum which reported a direct relationship between stress and hypertension ${ }^{10}$.

\section{CONCLUSION}

The findings of the present study highlighted the prevalence of hypertension is $6.1 \%$ among students at Al-Azhar University. The blood pressure values increased with associated factors (age, sex, BMI, smoking stress, physical activity, and family history). The most prevalent associated factors for hypertension in this study were positive family history $(65.2 \%)$ followed by excessive salt in diet $(58.7 \%)$, stress $(55.4 \%)$, smoking $(47.8 \%)$, Obesity 
(26.1\%) and Physical activity (1.1\%). The current results were recommended that a periodic screening and monitoring of blood pressure of students should be incorporated into the university entrance physical examination, and university students' health education on hypertension as a disease and its associated factors should be strengthened.

\section{REFERENCES}

1. Chmiel-Połeć $Z$ and Cybulska I. Smoking and other risk factors of cardiovascular diseases, connected with arteriosclerosis among youth. PrzeglLek., 2008; 65 (10):437-45.

2. Buttar H, Li T and Ravi N. Prevention of cardiovascular diseases: Role of exercise, dietary interventions, obesity, and smoking cessation. ExpClinCardiol., 2005; 10 (4):22949.

3. World Health Organization and International Society of Hypertension Writing Group. International society of hypertension writing group: 2003 world health organization (WHO)/International Society of hypertension (ISH) statement on management of hypertension. J Hypertension., 2003;21 (11): 1983-92.

4. Chiolero A, Paradis G, Madeleine G, et al. Discordant secular trends in elevated blood pressure and obesity in children and adolescents in a rapidly developing country. Circulation, 2009;119 (4):558-565.

5. Ashour Z, Ibrahim M, Appel L, et al. The Egyptian National Hypertension Project (NHP): design and rationale. The NHP Investigative Team. Hypertension, 1995 (26): 880-885.

6. Viera A. Screening for hypertension and lowering blood pressure for the prevention of cardiovascular disease events. Med Clin North Am., 2017; 101 (4):701-712.

7. Siu A. Screening for high blood pressure in adults: US Preventive Services Task Force recommendation statement. Ann Intern Med., 2015; 163(10):778-86.

8. Bucher B, Ferrarini A, Weber N, et al. Primary hypertension in childhood. CurrHypertens Rep., 2013; 15(5):444-52.

9. Boujnah R, Nazek L, Maalej $M$, et al. Hypertension in Tunisian adults attending primary care physicians (ETHNA-Tunisia). Indian Heart J., 2018; 70(4):544-547.

10. Soliman M, El-Salamony O, El-KhashabK A, et al. Study of Hypertension among Fayoum University Students. International Journal of Public Health Research. 2014; 2(2): 15-19.

11. Moussa M, El-Mowafy R, and El-Ezaby H. Prevalence of hypertension and associated risk factors among university students: Comparative study. Journal of Nursing Education and Practice, 6: 19-27.

12. Naim N, Çetinkaya S, Yilmaz A, et al. Prevalence of Hypertension among High School Students in a Middle Anatolian Province of Turkey. Health PopulNutr., 2008; 26(1): 88-94.
13. Abd El-Mohsen A, Abd El Maksoud M, and Shokier T. Prevalence of hypertension among youth at Helwan University. Life Sci J., 2013; 10(3): 2304-2308.

14. Sundar J, Adaikalam J, Parameswari S, et al. Prevalence and determinants of hypertension among urban school children in the age group of 13-17 Years in, Chennai, Tamilnadu. Epidemiol., 2013; 3: 130.

15. Oladapo O, Salako L, Sodig O, et al. A prevalence of cardiometabolic risk factors among a rural Yoruba south-western Nigerian population: A population-based survey. Cardiovasc J Afr., 2010; 21: 26-31.

16. Pang W, Li Z, Sun Z, et al. Prevalence of hypertension and associated factors among older rural adults: results from Liaoning Province. China. Med PrincPract., 2010; 19(1): 22- 27.

17. Ibrahim M, Rizk H, Apple $L$, et al. Hypertension, prevalence, awareness, treatment, and control in Egypt. Results from the Egyptian National Hypertension Project (NHP). Hypertension 1995. (26) (6 Pt 1) :886890.

18. Ibrahim B. Prevalence and related risk factors of essential hypertension in the Jazan region, Saudi Arabia. Sudanese Journal of Public Health, 2011; 6(2): 54-50.

19. World Health Organization. Global Status Report on Non-communicable Diseases 2010. Geneva: World Health Organization; 2011 